\title{
DNA-directed RNA Polymerase
}

National Cancer Institute

\section{Source}

National Cancer Institute. DNA-directed RNA Polymerase. NCI Thesaurus. Code C17104.

An enzyme that catalyzes the stepwise addition of ribonucleotides to the 3' end of a growing RNA chain using a single-stranded DNA template. This reaction, transcription, is important in the flow of information from DNA to proteins. Three different polymerase protein complexes have been identified and characterized. 